\title{
Improving the echocardiographic prediction of systolic anterior motion risk following mitral repair
}

\author{
B Popa 1* G Musica², G Cerin ${ }^{3}$, L Zamfir ${ }^{3}$, M Diena $^{2}$ \\ From 23rd World Congress of the World Society of Cardio-Thoracic Surgeons \\ Split, Croatia. 12-15 September 2013
}

\section{Background}

One of the possible complications following the mitral valve repair is the systolic anterior motion (SAM) of the anterior mitral leaflet. The preoperative echocardiographic examination is essential for the identification of the patients at risk for this situation. The most frequently used indicators are the ratio between the AML and PML (AP ratio) and the distance from the coaptation line to the interventricular septum (C-Sep). When repair of significantly redundant valves is performed additional parameters for SAM risk evaluation might be needed.

Objective was to investigate if the length of the mitral leaflets might be considered an additional parameter for the preoperative estimation of SAM risk.

\section{Methods}

From March 2008 till December 2011, 159 patients (105 male) underwent complex mitral valve repair for degenerative mitral regurgitation. The SAM risk was evaluated using the classically described AP ratio (when smaller than 1.3) and the C-Sep (when smaller than $25 \mathrm{~mm}$ ); in addition a third parameter was introduced; namely the mitral leaflet length (when longer than $35 \mathrm{~mm}$ ).

\section{Results}

The prevalence of the postoperative SAM following complex MV repair was 0,012 (two out of 159 pts) which is much lower than the published date over this situation (from about 2 to $16 \%$ ).

\section{Conclusion}

The length of the mitral valve leaflets is a valid adjunctive parameter for the prediction and avoidance of postoperative SAM. This information is fundamental for the surgical team as it provides a correct surgical planning.

\section{Authors' details}

${ }^{1}$ Cardiac Ultrasonography Dpt, San Gaudenzio Clinic, Novara, Italy. ${ }^{2}$ Cardiac Surgery Dpt, San Gaudenzio Clinic, Novara, Italy. ${ }^{3}$ Cardiology Dpt, San Gaudenzio Clinic, Novara, Italy.

Published: 23 October 2013

doi:10.1186/1749-8090-8-S2-O2

Cite this article as: Popa et al: Improving the echocardiographic prediction of systolic anterior motion risk following mitral repair. Journal of Cardiothoracic Surgery 2013 8(Suppl 2):O2.
Submit your next manuscript to BioMed Central and take full advantage of:

- Convenient online submission

- Thorough peer review

- No space constraints or color figure charges

- Immediate publication on acceptance

- Inclusion in PubMed, CAS, Scopus and Google Scholar

- Research which is freely available for redistribution
C Biomed Central

\section{Biomed Central}

(c) 2013 Popa et al; licensee BioMed Central Ltd. This is an Open Access article distributed under the terms of the Creative Commons Attribution License (http://creativecommons.org/licenses/by/2.0), which permits unrestricted use, distribution, and reproduction in any medium, provided the original work is properly cited. 